\title{
O Trabalho do Assistente Social no cuidado com Mulheres em Situação de Vulnerabilidade Social na Atenção Básica do SUS
}

\author{
The work of the Social Worker in care with Women in Social Vulnerability Situation in the \\ Primary care of SUS
}

\author{
Graziela Dourado Ramos* \\ Rosa Maria Castilhos Fernandes **
}

\section{Resumo}

Este artigo reflete a importância do trabalho da Assistente Social na Atenção Básica do Sistema Único de Saúde. Socializa resultados de pesquisa documental e qualitativa que objetivou analisar perfil, necessidades em saúde e instrumentalidade do trabalho com 10 mulheres em situação de vulnerabilidade social: vítimas de violência e usuárias de drogas. Entre os documentos analisados: prontuários e formulários de atendimento do Serviço Social em uma Unidade Básica de Saúde - UBS. Nos resultados destacaram-se: perfis de mulheres negras, trabalhos precarizados, mães, ensino fundamental incompleto e renda familiar de menos de 1 até 4 salários mínimos. As necessidades em saúde dessas mulheres se constituem em demandas para equipe técnica da UBS e relacionam-se à saúde mental, doenças crônicas, infecções sexualmente transmissíveis (IST), violência doméstica e uso de substâncias psicoativas. O trabalho da Assistente Social é interprofissional e intersetorial com articulações de diferentes políticas públicas. Há um planejamento do processo de trabalho, análise das demandas, ações de educação em saúde, mediação para acesso aos direitos sociais e avaliação deste processo. Conclui-se que o trabalho da assistente social na equipe da Unidade de Saúde é extremamente relevante para intervir nos determinantes e condicionantes de mulheres em situação de vulnerabilidade social.

Palavras-chave: Serviço social. Atenção básica em saúde. Mulheres. Vulnerabilidade Social. SUS.

\section{Abstract}

This article reflects the importance of the work of the Social Worker in the Primary care of "Sistema Único de Saúde". Socialize a documentary and qualitative research results that aimed to analyze the profile, health needs and instrumentality of Social Worker with women in situations of social vulnerability in a Health Unit. Among the documents analyzed are medical records and forms of attendance of the Social Service in a Health Unit. Research subjects refer to 10 women, intentionally chosen, in situations of social vulnerability who suffer violence and drugs abuse. The results: profile of black women with precarious work, mothers, incomplete elementary school and family income from less than 1 to more than 4 minimum wages. Health needs are related to mental health, chronic diseases and STDs, domestic violence and use of psychoactive substances. The work is an interprofessional and intersectoral with articulations of different public policies. There is a work process planning, demands analysis, health education actions, mediation for access to social rights and the intervention process. It is concluded that the work of the social worker in the Health Unit is extremely relevant to intervene in the determinants and constraints of women in situations of social vulnerability.

Keywords: Social Worker. Primary Care. Women. Social vulnerability. SUS.

\footnotetext{
* Assistente Social. Especialização em Atenção Básica em Saúde pelo Hospital de Clínicas de Porto Alegre HCPA/UFRGS. Mestranda em Serviço Social pelo Instituto Superior Miguel Torga (ISMT), Coimbra - PT.

** Assistente Social. Mestrado e Doutorado em Serviço Social pela Pontifícia Universidade Católica do Rio Grande do Sul, com estágio de doutorado no Instituto de Psicologia e Ciências da Educação da Universidade do PortoPortugal. Professora Adjunta do Departamento de Serviço Social e Vice Coordenadora do Programa de Pós Graduação em Política Social e Serviço Social /Instituto de Psicologia da Universidade Federal do Rio Grande do Sul (UFRGS).
} 


\section{Introdução}

A conjuntura política, social, econômica e cultural que se vive nestes tempos, não só vêm ameaçando as políticas sociais brasileiras, como vêm implementando uma série de medidas que destituem significativas conquistas da classe trabalhadora, como por exemplo, as que atingem diretamente o Sistema Único de Saúde (LEI 8.080/1990), em sua estrutura organizacional e, consequentemente, os direitos à saúde (BRASIL, 1990). É urgente a discussão sobre os cortes orçamentários no campo da saúde que se materializam com a aprovação, em outubro de 2016, da PEC 241, que altera a Constituição Federal de 1988 (BRASIL, 1988) para congelar, por duas décadas, os investimentos em saúde e educação, entre outras políticas públicas.

Nesse sentido, se faz necessário lembrar que o Sistema Único de Saúde (SUS) é resultado de conquistas de lutas populares e do processo de redemocratização vivenciado no país nos anos 1980-1990 (BRAVO; MATOS, 2009). Esse sistema vive atualmente uma de suas maiores crises, pois seus princípios vêm sendo questionados por conta da prevalência e defesa dos processos de produção e reprodução do capital e que acabam por defender a privatização da saúde, a retração do Estado na condução e responsabilização com os serviços de saúde pública, prestados em todo território nacional. Além disto, a onda do neoconservadorismo apresenta-se, então, como

[...] forma dominante de apologia conservadora da ordem capitalista, combatendo o Estado social e os direitos sociais, almejando uma sociedade sem restrições ao mercado, reservando ao Estado a função coercitiva de reprimir violentamente todas as formas de contestação à ordem social e aos costumes tradicionais (BARROCO, 2015, p. 625).

Assim sendo, a retração dos investimentos na Atenção Básica em Saúde (ABS) é defendida por segmentos conservadores e neoliberais que encabeçam a disputa pela saúde. Sabe-se que o SUS, ao longo de sua institucionalização, sempre sofreu ameaças ditadas pelo capital, mas tem que se reconhecer que a conjuntura que se configurou a partir dos anos de 2016, no Brasil, tem sido categórica com relação à destituição dos investimentos nesse sistema, entre outros aspectos. Importante sublinhar que o termo adotado e defendido neste artigo "Atenção Básica em Saúde" é pelo fato de que o "Movimento Sanitário Brasileiro teria 
buscado uma diferenciação ideológica em relação ao reducionismo presente na ideia de Atenção Primária, com o objetivo de construção de um sistema público universal em uma concepção de cidadania ampliada" (GIOVANELLA, 2018, p. 1).

Diferentes situações caracterizam este contexto como, por exemplo, a falta de recursos humanos e a precarização da gestão do trabalho, a escassez e o sucateamento de tecnologias, enfim de condições para a realização do trabalho concreto dos profissionais que compõem a ABS. Entretanto, é possível identificar que mesmo com essa conjuntura, muitos são os trabalhadores da saúde que buscam formas de resistência e enfrentamento das adversidades dessa política social. Defendendo o SUS e a responsabilidade Estatal como um sistema universal, gratuito e de qualidade na provisão de seus serviços, sejam eles no âmbito dos serviços públicos, ou nas iniciativas privadas que prestam essa atenção em saúde por meio de recursos públicos. Entretanto, as necessidades em saúde se materializam por meio das demandas que se apresentam no trabalho cotidiano dos profissionais que atuam nos diferentes serviços e programas da saúde. E que requerem intervenções técnico-operativas, nesse caso, interessa refletir acerca da importância do trabalho das Assistentes Sociais na Atenção Básica em Saúde.

Historicamente, o campo da saúde tem sido um espaço sócio-ocupacional de destaque para a atuação das Assistentes Sociais, ao lado de outras profissões da saúde. 0 Serviço Social vem produzindo conhecimentos na área da saúde, assim como, vêm construindo estratégias de trabalho e de militância que defendem a reforma sanitária e a saúde coletiva. Bravo e Matos (2009, p. 11) afirmam que "o debate do Serviço Social na Saúde vem acompanhado de uma referência ao projeto da reforma sanitária e ao projeto éticopolítico profissional, por mais que, muitas das vezes, não explicitamente".

Uma das discussões emergentes no âmbito do Serviço Social se refere à importância do trabalho das Assistentes Sociais na ABS, tendo em vista que na Política de Atenção Básica (BRASIL, 2017) este profissional não está previsto na equipe da Estratégia Saúde da Família (ESF), apenas nos Núcleos de Apoio à Saúde da Família (NASF). Nessas equipes, a/o assistente social tem como objetivo requisitar o reforço de ações de apoio institucional e/ou matricial, mas que não são exclusivas desse profissional, tais como: análise e intervenção sobre riscos e vulnerabilidades, apoio às informações e indicadores de saúde, organização do processo de trabalho que se refere ao acolhimento, cuidado, ações coletivas, gestão, articulação com outros pontos de atenção da rede, vivências de educação permanente, utilização de 
O Trabalho do Assistente Social no cuidado com Mulheres em Situação de Vulnerabilidade Social...

dispositivos de gestão do cuidado, entre outros (BRASIL, 2012). Sabe-se que ações de apoio institucional e/ou matricial são completamente diferentes de intervenções diretas aos usuários a partir de um planejamento interprofissional e intersetorial. Além disso, é contraditório ao se pensar que há um reconhecimento que se expressa na formação especializada para Assistentes Sociais como parte de uma equipe de ESF na ABS por meio das Residências Multiprofissionais em Saúde.

A busca pelo aprimoramento destas e outras questões, no campo da política de saúde, permite a oferta de serviços qualificados e apropriados para responder às situações complexas, possibilitando a redução de danos, promoção, prevenção da saúde e a restauração da vida humana (SPOSATI, 2009) e isto requer cada vez mais o trabalho interprofissional nas equipes de uma UBS e ESF. A violência contra as mulheres, considerada como uma questão de saúde pública e relacionada aos determinantes sociais, é um exemplo de risco associado à situação de vulnerabilidade social. Sabe-se que a violência de gênero vem sendo cada vez mais debatida na sociedade brasileira, porém, faz-se necessário o aprofundamento científico e teórico para incidir de forma eficaz diante desta problemática que se expressa em serviços de diferentes políticas sociais.

Assim sendo, este artigo emerge das reflexões de uma experiência em Residência Integrada Multiprofissional em Saúde (RIMS) vivenciada em um hospital público, e socializa os resultados de uma pesquisa que teve como objetivo evidenciar as necessidades em saúde de mulheres em situação de vulnerabilidade social e o trabalho realizado pela Assistente Social em uma Unidade de Saúde, visando à legitimação desse espaço profissional, assim como, para contribuir na qualificação dos serviços prestados no SUS. Os objetivos específicos do estudo se propuseram: analisar o perfil de mulheres vítimas de violência e/ou usuárias de álcool e outras drogas, que acessam o Serviço Social em uma Unidade de Saúde; identificar as necessidades em saúde dessas mulheres e analisar a instrumentalidade do trabalho da Assistente Social.

Para fins de sistematização, este artigo está organizado, além desta introdução, em três seções. Na primeira discorre-se sobre a metodologia da pesquisa, apresentando a questão central, questões norteadoras, fonte de dados, sujeitos da pesquisa e relato do processo de investigação. Na segunda seção, apresenta-se a reflexão acerca dos resultados do perfil e das necessidades em saúde dos sujeitos da pesquisa. Já na terceira, os resultados referentes ao trabalho e à instrumentalidade da Assistente Social no cuidado com mulheres 
em situação de vulnerabilidade social, no campo da Atenção Básica do SUS. São discutidos, tendo como base as referências teóricas que subsidiaram esta investigação. Por fim, as considerações finais apresentam os achados da pesquisa de forma sintetizada, conforme os objetivos elaborados.

\section{Metodologia}

A pesquisa ${ }^{1}$ intitulada "O trabalho do Assistente Social com mulheres em situação de vulnerabilidade social na Atenção Básica", de caráter qualitativo, descritivo e documental, procurou responder à seguinte questão central: de que maneira o trabalho da Assistente Social vem contribuindo com a atenção à saúde de mulheres em situação de vulnerabilidade social no âmbito da Atenção Básica em Saúde?

Como principais documentos de análises, destacou-se os prontuários eletrônicos das usuárias, formulários de atendimento do Serviço Social, além de estudos e relatórios sociais elaborados pela equipe de assistentes sociais da UBS. Os sujeitos da pesquisa foram escolhidos de forma não aleatória e intencional (GIL, 2012), tendo como critérios de inclusão: 48 mulheres que foram atendidas pelo Serviço Social, no período de março de 2017 a fevereiro de 2018 na UBS; em situação de vulnerabilidade social, expostas aos riscos sociais de: violência e/ou abuso de álcool e outras drogas. E os critérios de exclusão foram: mulheres em situação de vulnerabilidade social, que não pertencem ao território de abrangência, não cadastradas na UBS e menores de 18 anos. Entretanto foram escolhidas intencionalmente 10 mulheres das 48 atendidas pelo Serviço Social, por apresentarem maior quantidade e qualidade de informações registradas nos documentos de análise.

Para a coleta de dados por meio da pesquisa nos documentos já citados, foi utilizado um instrumento na plataforma virtual do Googleforms, constituindo-se de 42 questões abertas e fechadas. Este instrumento de coleta de dados possibilitou a análise quantitativa (percentual) e qualitativa de 10 prontuários eletrônicos, 9 formulários de atendimento do Serviço Social (que é composto de informações referentes: aos dados de identificação, à composição familiar, à situação habitacional, ao contexto familiar, à situação atual de saúde e rede social, aos aspectos intersetoriais e assistenciais, à organização e planejamento das ações e avaliação do acompanhamento) e 8 estudos e relatórios sociais. Portanto, totalizando

\footnotetext{
${ }^{1}$ A pesquisa teve aprovação pela Plataforma Brasil, sob o no CAAE 81811417.6.0000.5327, em fevereiro de 2018, e pelo Comitê de Ética e Pesquisa do Hospital ----, em agosto de 2018.
} 
O Trabalho do Assistente Social no cuidado com Mulheres em Situação de Vulnerabilidade Social...

28 documentos institucionais analisados e 42 informações coletadas de cada sujeito da pesquisa.

A análise qualitativa se realizou por meio da análise de conteúdo (BARDIN, 2016) das informações coletadas pelo instrumento elaborado. Portanto, esta análise ocorreu a partir da relação das categorias iniciais com as questões norteadoras da investigação, assim como aquelas que emergiram do processo de análise e que se constituem nos resultados deste estudo. Portando, são as questões norteadoras: primeira - "Qual o perfil de mulheres em situação de vulnerabilidade social atendidas pelo Serviço Social na UBS em estudo?"; segunda - "Quais são as necessidades em saúde identificadas pelo Serviço Social de mulheres em situação de vulnerabilidade social?"; e terceira - "O que faz parte da instrumentalidade da Assistente Social no trabalho com mulheres em situação de vulnerabilidade social em uma Unidade de Saúde?". Desta forma, emergiram categorias neste processo analítico que estão demonstradas nos resultados da pesquisa, e aqui subdivididas em dois itens, sendo um sobre as mulheres e o outro sobre o trabalho realizado pelo Serviço Social da UBS em estudo.

\section{As Mulheres em Situação de Vulnerabilidade social: Usuárias da Atenção Básica em Saúde}

Vulnerabilidade social está relacionada diretamente, pelo menos, a um risco social, incluindo a ideia de estar mais suscetível a que algo ocorra. Inicialmente, é importante compreender que as manifestações dos riscos ocorrem no cotidiano das pessoas, nos territórios onde vivem, sendo o precário acesso à infraestrutura um dos fatores de risco e/ou agravos de situações de vulnerabilidade social. Ou seja, os riscos se relacionam diretamente com a vida e o modo de viver, que são determinados pelas condições sociais em que vivem, fazendo-se necessário considerar como altos fatores de risco as questões relacionadas à etnia, gênero, religião e orientação sexual (SPOSATI, 2009). Portanto, estar em situação de vulnerabilidade significa estar sujeitado por algumas vivências e capacidades que já estão postas pela sociedade capitalista. Sabe-se que mulheres fazem parte de uma das populações mais vulnerabilizadas na sociedade brasileira, vivenciando diariamente violações de direitos civis, sociais e humanos.

As 10 mulheres, sujeitos da pesquisa, apresentam um perfil de $80 \%$ na fase adulta (de 20 a 50 anos) e $20 \%$ idosas (72 e 88 anos). São mulheres negras, sendo que $60 \%$ se 
autodeclararam "pretas" e 40\% "brancas" ao fazer os cadastros na Unidade de Saúde, através do sistema nacional E-SUS (BRASIL, 2013). Sobre o acesso ao emprego, $20 \%$ se encontra desempregada; as $80 \%$ que trabalham apresentam uma precarização do trabalho, tendo em vista que se destacam os trabalhos em supermercados e em reciclagem. As mulheres que trabalham em supermercados possuem carteira de trabalho e as que trabalham com reciclagem são autônomas e não contribuem para a Previdência Social, ou seja, sem nenhuma proteção social em caso de necessidade de afastamento e sem contribuição para fins de aposentadoria. Também há mulheres que laboram com vendas, trabalho doméstico, costura ou são donas de casa. Das mulheres que não estão no mercado de trabalho formal $40 \%$ gostaria de se inserir.

Sobre o acesso à educação, o nível é de baixa escolaridade, pois 70\% possuem ensino fundamental incompleto, $20 \%$ ensino fundamental completo e $10 \%$ ensino superior incompleto, o que demonstra uma grande evasão escolar ainda no período da infância. Essas mulheres são todas mães, de 3 ou mais filhos (40\%), de apenas 1 filho (40\%) ou em menor proporção de 2 filhos (20\%). A renda familiar varia de menos de 1 salário mínimo até 4 salários mínimos. Esse perfil de mulheres se relaciona diretamente com os dados apresentados no Mapa da Violência - Homicídio de Mulheres no Brasil, do ano de 2015, onde apresenta que o homicídio feminino é predominante na fase adulta, na faixa de 18 a 30 anos de idade e que a população negra é vítima prioritária da violência homicida no país e por esse motivo, nos últimos anos, o índice de vitimização da população negra cresceu de forma drástica (WAISELFISZ, 2015).

Conhecer o perfil e identificar os riscos sociais que condicionam as pessoas a se encontrarem em situações de vulnerabilidade social é de extrema relevância para os serviços, principalmente no setor da $A B S$, pelos serviços se localizarem no território onde os sujeitos vivem. Nesse sentido, as vulnerabilidades sociais, no setor da saúde, estão diretamente relacionadas às condicionantes e determinantes implicados no processo saúde-doença e que estão relacionados com a estrutura da sociedade capitalista e das sequelas da desigualdade social brasileira. Por isto, o atendimento dessas demandas deve-se dar por meio de um Plano Terapêutico Singular (PTS) que articule a proteção social, reduza danos e trabalhe com as potencialidades dos sujeitos a partir da educação em saúde. Mas, para planejar este cuidado singular é imprescindível conhecer as necessidades das mulheres que são usuárias dos serviços de saúde. 
O Trabalho do Assistente Social no cuidado com Mulheres em Situação de Vulnerabilidade Social...

É preciso reconhecer que há uma tendência histórica do acesso aos serviços de saúde majoritariamente pela população do gênero e sexo feminino. Aponta-se a saúde da mulher como uma das áreas temáticas preconizadas pelo Ministério da Saúde (MS), refletindo na organização das ações e dos serviços (CAMARGO; MENDES, 2012, p. 298). O protocolo da Atenção Básica em Saúde das Mulheres (BRASIL, 2016) orienta quanto: à atenção no pré-natal de baixo risco, ao puerpério e promoção do aleitamento materno, ao planejamento reprodutivo, à prevenção do câncer de colo do útero e do câncer de mama, à atenção no climatério e atenção à situação de violência sexual e/ou doméstica/intrafamiliar. Apresentase como desafio enxergar as necessidades de saúde das mulheres para além das questões reprodutivas e individuais.

As mulheres, sujeitos desta pesquisa, demonstraram fazer acompanhamento em UBS para necessidades em saúde mental, doenças crônicas e infecções sexualmente transmissíveis (IST), como por exemplo: Depressão, Hipertensão, HIV/AIDS, Transtorno de Humor Bipolar (THB), além do abuso de substâncias psicoativas, que é critério de inclusão da pesquisa. É possível analisar a predominância da condição crônica que abarca uma categoria extremamente vasta de agravos, doenças transmissíveis, não transmissíveis e incapacidades. Estas requerem a continuidade do cuidado para o enfrentamento, pois constituem problemas de saúde que exigem um gerenciamento contínuo por um longo período (CONASS, 2009). Além disso, esses agravos se relacionam com a violência e causas externas. Segundo a Organização Mundial da Saúde (2015, p. 8):

[...] a violência contribui para problemas de saúde ao longo da vida - principalmente para mulheres e crianças - e para morte prematura. Muitas das principais causas de morte - como doenças cardíacas, acidentes vasculares, câncer e HIV/Aids decorrem de comportamentos como tabagismo, consumo inadequado de álcool e drogas, e sexo inseguro, que as vítimas adotam em um esforço para lidar com o impacto psicológico da violência.

Isto reflete a vulnerabilidade social em que essas mulheres se encontram, que também se reflete nos seus corpos. Por isto, a importância de obterem acesso à informação e de se identificar e fortalecer as redes de apoio e de cuidado à saúde, que devem ser sempre objetivos das equipes de saúde. Importante destacar que $80 \%$ das mulheres só acessam a UBS e $20 \%$ também acessam serviços especializados, como por exemplo: SAE - Serviço de Assistência Especializada em HIV/AIDS. Ou seja, a Unidade de Saúde pode ser considerada como referência no cuidado à saúde dessas mulheres. Isto reflete o desafio posto às equipes 
de Atenção Básica em Saúde em garantir a coordenação do cuidado e pela complexidade das demandas. Contraditoriamente, é sabido que a ABS, por muitos governos, é o setor da saúde que menos recebe recursos financeiros e incentivos.

No aprofundamento sobre a rede de apoio dessas mulheres, foi possível identificar que $70 \%$ possuem auxílio de familiares para o enfrentamento de problemas e nos cuidados voltados à saúde, como por exemplo, de filhas, companheiros e amigos. Porém, ao mesmo tempo em que as mulheres sinalizam seus companheiros como rede de apoio, muitas vezes, eles também são os seus agressores. Especificamente relacionado a isso, identificou-se que $90 \%$ vive ou já viveu em uma situação de violência. Destacando-se a violência emocional ou psicológica em $50 \%$ dos casos, causada em $10 \%$ por empregadores (sem distinção do sexo) e em $90 \%$ por agressores homens, sendo estes: $30 \%$ companheiros, $20 \%$ filhos, $20 \%$ pais e $20 \%$ irmãos. Em menor proporção, as agressoras mulheres: $20 \%$ são mães e $10 \%$ são filhas. Os dados dos agressores ultrapassaram 100\% porque algumas mulheres sofreram violência por mais de um familiar ao longo da vida.

Sobre a violência de gênero é preciso compreendê-la como uma relação de poder, da dominação do homem pela submissão da mulher. Esses comportamentos fazem parte de um processo sociocultural e civilizatório, através da diferenciação da educação para homens e para mulheres, o que acaba por induzir e fortalecer estereótipos (LISBOA; PINHEIRO, 2005). A partir da violência de gênero, ocorre a violência doméstica ou violência intrafamiliar, que segundo Minayo (2007, p. 34-35) se refere ao mesmo problema e dizem respeito aos conflitos familiares transformados em "intolerância, abusos e opressão". E a violência de natureza psicológica "nomeia agressões verbais ou gestuais com o objetivo de aterrorizar, rejeitar, humilhar a vítima, restringir-lhe a liberdade ou, ainda, isolá-la do convívio social. Indica também a rejeição de pessoas, na inter-relação" (MINAYO, 2007, p. 39).

Sabe-se que a violência praticada por parceiro íntimo é um importante fator de risco para HIV, gravidez indesejada e outros problemas de saúde. Essas mulheres têm uma probabilidade duas vezes maior de apresentar distúrbios relacionados à ingestão de álcool, de ter depressão e maior risco de suicídio comparado a mulheres que não foram expostas a esse tipo de violência (ORGANIZAÇÃO MUNDIAL DE SAÚDE, 2012). Além disso, a violência praticada por parceiro íntimo pode afetar negativamente o desenvolvimento de crianças (ORGANIZAÇÃO MUNDIAL DE SAÚDE, 2015), sendo a violência diretamente associada aos determinantes sociais, como insuficiência e ineficácia dos governos, do estado de direito, 
normas culturais e sociais, desemprego, desigualdade de renda e de gênero, rápidas mudanças sociais e poucas oportunidades no âmbito da educação (ORGANIZAÇÃO MUNDIAL DE SAÚDE, 2015).

Segundo a Organização Mundial da Saúde (2015), há fatores transversais de risco, como acesso às armas de fogo e consumo excessivo de álcool. Portanto, é urgente o estabelecimento de estratégias de prevenção à violência para diminuir esses riscos ou para a prevenção dos mesmos. Assim, o trabalho de prevenção da violência tem que passar pela desconstrução de crenças e culturas discriminatórias, que reproduzem as relações de poder, no que se refere à educação de homens e mulheres e sobre a maneira de se relacionarem, para que se possa enfrentar a cultura vigente patriarcal e machista.

Outro aspecto se refere ao uso de substâncias psicoativas que foi identificado em $40 \%$ das mulheres, sendo que, de 4 mulheres, 3 utilizavam/utilizam álcool. Apenas em uma das mulheres havia o registro sobre a frequência e quantidade utilizadas, sendo esta informação importante para o cuidado de pessoas que fazem abuso de álcool e outras drogas. Essas mulheres apresentam problemas, principalmente nas relações familiares. Estes problemas foram identificados tanto pelas próprias mulheres quanto pela equipe da UBS. Em relação a este problema de saúde, deve-se cuidar para que a abstinência não seja o único objetivo da atenção prestada pelos profissionais de saúde. Afinal, o plano terapêutico deve estar atrelado às singularidades de cada sujeito e com as diferentes possibilidades, demandas e escolhas. Além disso, se faz necessário uma prática acolhedora e que incentive a autonomia e participação dos usuários (BRASIL, 2003), principalmente no que se refere ao uso de substâncias psicoativas, que é visto socialmente como algo marginalizado e discriminado pela população em geral, se potencializando quando os sujeitos são mulheres e mães.

As mulheres, segmento populacional significativo como sujeitos de direitos e usuárias das Unidades de Saúde, dão visibilidade à desproteção social a que a população está submetida, que se materializa no cenário atual de ameaças constantes aos direitos sociais já conquistados. Nesse sentido, Merhy e Franco (2008, p. 282) afirma que:

[...] por isso, advogamos que nas sociedades de direito à saúde, como é a brasileira, de acordo com sua constituição de 1988, o 'trabalho em saúde' deve pautar-se pelo 'referente simbólico': ato de cuidar da vida, em geral, e do outro, como se isso fosse de fato a alma da produção da saúde. E, assim, tomar como seu objeto central o mundo das necessidades de saúde dos usuários individuais e coletivos, expressos como demandas pelas ações de cuidado. 
Devido a esta complexidade, não há trabalhador da saúde sozinho ou uma área do conhecimento apenas que consiga dar conta do mundo das necessidades de saúde, o objeto real do 'trabalho em saúde' (MERHY; FRANCO, 2008). Ainda segundo Cecílio (2001) essas necessidades podem ser classificadas, em quatro conjuntos: 1) boas condições de vida; 2) acesso às grandes tecnologias que melhoram ou prolongam a vida; 3) criação de vínculos afetivos entre usuários e profissional/equipe de saúde; 4) graus de crescente autonomia que cada pessoa tem no seu modo de conduzir a vida; que auxiliam a compreender os fatores determinantes e condicionantes implicados no processo saúde-doença. É então esse contexto que vem caracterizando a realidade dessas mulheres que provoca a reflexão acerca do trabalho das assistentes sociais que atuam em unidades de saúde se deparam com as necessidades e demandas dessas usuárias.

\section{O trabalho da Assistente Social com Mulheres em Situação de Vulnerabilidade Social em uma Unidade de Saúde: desafios e possibilidades}

O trabalho é carregado de contradições, pois ao mesmo tempo "emancipa e aliena, humaniza e sujeita, libera e escraviza" (ANTUNES, 2018, p.26) e por isto refletir acerca dessa realidade do ato de trabalhar tem sido central nas discussões deflagradas pelo próprio Serviço Social em seus fundamentos. Para Antunes (1999, p. 102), especificamente no setor da saúde, se refere a um trabalho improdutivo,

[...] cujas formas de trabalho são utilizadas como serviço, seja para o uso público ou para o capitalista, e que não se constituem como elemento diretamente produtivo, como elemento vivo do processo de valorização do capital e de criação de mais-valia (ANTUNES, 1999, p. 102).

Isto faz refletir sobre o reconhecimento e análise das diferentes expressões e manifestações da Questão Social, entendida como: o conjunto das manifestações das desigualdades sociais da sociedade capitalista e as formas de resistência da classe trabalhadora nas lutas por acesso aos bens, direitos e serviços (IAMAMOTO, 2012). Essas determinações se expressam na vida dos sujeitos e são trazidas pelos usuários dos serviços, sendo o Estado responsável em intervir. Importante reafirmar que o Serviço Social é uma profissão inserida na divisão sociotécnica do trabalho, portanto trata-se de um trabalho especializado e coletivo (BRASIL, 1993). 
Nesse sentido, o trabalho utilizado como serviço para uso público, necessita de uma instrumentalidade para o cuidado em saúde de mulheres em situação de vulnerabilidade social e faz-se necessário contextualizar o espaço ocupacional. A UBS investigada tem como área de abrangência 40 mil pessoas sendo $28 \mathrm{mil}^{2}$ cadastradas no serviço. A Unidade segue um modelo misto, sendo composta de 4 áreas divididas entre ESF e UBS, respectivamente 4 equipes (1 equipe não cadastrada). Conta com uma equipe ampla, multidisciplinar (Enfermagem, Medicina, Agente Comunitário de Saúde, Serviço Social, Nutrição e Farmácia) e é campo formativo para diversos profissionais de saúde.

As demandas para o Serviço Social, que são requisições de conhecimentos técnicos específicos, foram identificadas neste estudo como $70 \%$ advindas da própria equipe da UBS, 20\% demanda espontânea das mulheres e 20\% das escolas do território. Este cálculo ultrapassou os $100 \%$ por existirem demandas que foram concomitantes por diferentes portas de entrada. As demandas chegaram, por exemplo: por suspeitas de violência intrafamiliar por falta de cuidados e de higiene; organização de espaços comunitários por questões epidemiológicas (como histórico de surto de dengue), contribuir no acesso ao tratamento de saúde e acesso à alimentação. Ou seja, essas demandas foram relacionadas à suspeitas de violência e para orientações de acesso aos direitos sociais. Isto demonstra a importância do trabalho da Assistente Social na política de Atenção Básica em Saúde e a afirmação das particularidades de cada profissão, tendo em vista que:

[...] o assistente social tem tido, muitas vezes, dificuldades de compreensão por parte da equipe de saúde das suas atribuições e competências face à dinâmica de trabalho imposta nas unidades de saúde, determinadas pelas pressões com relação à demanda e à fragmentação do trabalho ainda existente. Entretanto, essas dificuldades devem impulsionar a realização de reuniões e debates entre os diversos profissionais para o esclarecimento de suas ações e estabelecimento de rotinas e planos de trabalho (CONSELHO FEDERAL DE SERVIÇO SOCIAL, 2010, p. 47).

Para o estabelecimento de rotinas e planos de trabalho, fundamentalmente, no que se refere à prevenção e promoção de saúde deve-se desenvolver conhecimentos, dados, metodologias e planejamento de intervenções sobre os riscos e vulnerabilidades sociais (SPOSATI, 2009). Para isto, há a necessidade de um planejamento enquanto movimento de reflexão-decisão-ação-reflexão da intervenção profissional (BAPTISTA, 2000) que perpassa na elaboração de objetivos, como por exemplo, de: contribuir no processo reflexivo/pedagógico

\footnotetext{
${ }^{2}$ Dados referente ao ano de 2017.
} 
e no acesso aos direitos sociais, articular e fortalecer espaços coletivos, aumentar a rede de apoio e de cuidado, elaborar estratégias para o enfrentamento de situações de risco, contribuir para o fortalecimento dos vínculos familiares. Além disso, neste planejamento é essencial o compartilhamento do cuidado com toda a equipe, evitando que haja fragmentação do cuidado. Isto se refere à interprofissionalidade, conceituada por Ceccim (2017, p. 50) como:

[...] uma condição principalmente de práticas colaborativas, o que inclui tudo aquilo que pertence ao campo - e que os núcleos cooperam em sua composição -, como tudo aquilo que podemos desenvolver como "núcleo comum" ou tudo aquilo que podemos realizar mediante apoio ou que não temos autonomia, exceto como membros de uma equipe.

Especificamente com a equipe do estudo, o compartilhamento do cuidado se deu, em $90 \%$, com a medicina de família e comunidade, em $50 \%$, com os agentes comunitários de saúde e, em $30 \%$, com a nutrição. Além das discussões dos casos em equipe e em reunião de rede, é possível identificar que a complexidade das necessidades dessas mulheres exige uma articulação com outras políticas. Em $90 \%$ os casos foram discutidos em reunião de rede intersetorial e encaminhados para serviços da política de Assistência Social, Ministério Público, Judiciário e serviços da política da Educação. Para Peduzzi (2017) o trabalho em equipe avançou no cotidiano dos serviços, principalmente na $A B S$, mais do que na própria formação dos profissionais da saúde, isso decorre da mobilização que as demandas dos usuários, famílias e comunidade provocam nos serviços de saúde, devendo inclusive ser dialogadas com a população.

Em relação aos resultados alcançados no cuidado com as mulheres em situação de vulnerabilidade social, sujeitos deste estudo, foram destacados: desligamento de abrigo de família, acesso ao trabalho, renda, benefícios sociais, maior consciência e autocontrole no uso de substâncias psicoativas, maior procura pelo atendimento dos serviços das políticas sociais, maior processo reflexivo e estratégias de enfrentamento para as violências vivenciadas, além de melhoras em sintomas clínicos e em saúde mental. Analisou-se que $90 \%$ dos acompanhamentos foram avaliados, a partir dos objetivos traçados inicialmente em relação aos resultados alcançados. E os objetivos não necessitaram ser modificados em $70 \%$ dos casos avaliados, sendo que em $30 \%$ necessitou de mudanças ao longo do acompanhamento. Todo processo avaliativo se constitui em mecanismos de extrema valia, principalmente por se 
O Trabalho do Assistente Social no cuidado com Mulheres em Situação de Vulnerabilidade Social...

destinar ao julgamento dos procedimentos e resultados adquiridos, a fim de indicar mudanças que sejam necessárias nos planos e na sua execução (FAGUNDES; MOURA, 2009).

Portanto, é possível verificar que o trabalho da Assistente Social de Unidade de Saúde vem corroborando no acompanhamento de mulheres em situação de vulnerabilidade social, contribui a partir de mediações para o acesso aos direitos sociais, para o fortalecimento de vínculos e contribuição de estratégias para o enfrentamento das situações impostas pela condição de vulnerabilização. A intencionalidade no atendimento às usuárias, por parte dos profissionais que atuam na saúde, é condição para que as necessidades sociais identificadas sejam de alguma maneira atendidas, incidindo na melhoria da saúde.

Para tanto, se faz necessário o avanço no que diz respeito ao investimento nas tecnologias ofertadas em uma Unidade de Saúde, para concretizar ações de promoção, proteção e prevenção. Uma estratégia para isto são os serviços se constituírem com equipes ampliadas e multiprofissionais, para além do que está previsto na legislação atual. Na defesa da saúde, enquanto direito social e responsabilidade do Estado, entende-se que o modelo de atenção que orienta as ações da equipe multidisciplinar deve direcionar-se "à efetivação de práticas democráticas, coletivas e de controle social, interdisciplinares, com vistas à integralidade e à intersetorialidade" (CAMARGO; MENDES, 2012, p. 291).

\section{Considerações Finais}

O propósito deste artigo não esgota a discussão acerca da importância do trabalho da Assistente Social na política da Atenção Básica em Saúde, especificamente no trabalho com mulheres em situação de vulnerabilidade social - vítimas de violência e/ou usuárias de substâncias psicoativas. Para, além disso, a ideia foi apresentar informações e reflexões a partir de resultados de pesquisa documental realizada em uma Unidade de Saúde do Sul do Brasil. Também é preciso que se diga que pesquisar tem se caracterizado como parte da instrumentalidade do trabalho profissional, sendo estratégico para a construção de ações que incidam de fato na realidade posta no âmbito da saúde e para melhoria das condições de vida, neste caso das mulheres usuárias da UBS lócus desta investigação.

Por meio da realização desta pesquisa, aqui socializada, analisou-se que o perfil é de mulheres negras, mães, com precarização do trabalho e baixa escolaridade. As necessidades em saúde se referem à atenção em saúde mental, doenças crônicas e infecções sexualmente transmissíveis (IST), necessitando de uma rede de apoio para o cuidado voltado à saúde e para 
enfrentamento de problemas. Ainda, são vítimas de violência doméstica e fazem uso de substâncias psicoativas, com prejuízo nas relações familiares.

Em relação ao trabalho da Assistente Social com esse público verifica-se que é realizado a partir de um labor interprofissional e intersetorial, com planejamento do processo de trabalho, análise das demandas, com educação em saúde, mediação para o acesso aos direitos sociais e avaliação do processo interventivo. Neste contexto, salientou-se o quanto o trabalho é um lócus de aprendizagens, de partilha de saberes, de reflexões críticas sobre o fazer profissional, de estudos sobre as necessidades dos sujeitos, enfim de experiências de educação permanente que não só transformam as realidades organizacionais do trabalho, mas os próprios trabalhadores humanizando assim suas relações em saúde.

Contudo, as mulheres em situação de vulnerabilidade social, assim como outros que usufruem dos serviços da saúde, representam um segmento populacional que exige atenção, respeito e qualificação dos profissionais e dos serviços ofertados, para intervir nos determinantes e condicionantes do processo saúde-doença. Outro aspecto importante de destacar é o quanto se faz necessária à ampliação de políticas e programas para o atendimento às mulheres vítimas de violência e usuárias de substâncias psicoativas, pois este recorte muitas vezes é excluído de diferentes formas pelos ideais conservadores e patriarcais da nesta sociedade.

Com relação à Residência Integrada Multiprofissional em Saúde, campo de formação especializada dos profissionais de saúde, é fundamental ampliar a discussão sobre a relevância do trabalho da Assistente Social na atenção básica, socializando cada vez mais os resultados alcançados em defesa dos direitos à saúde, da população usuária do SUS, que são cotidianamente mediados pela intervenção deste profissional, nos coletivos em que se inserem. Isto faz refletir, também, sobre a relevância de se alcançar um Sistema Único de Saúde que qualifique os atendimentos, as equipes e os recursos necessários para a política de Atenção Básica em Saúde. Afinal, é a política que deve realizar ações no território a partir da educação em saúde, redução de danos, promoção e prevenção de agravos.

\section{Referências}

ANTUNES, Ricardo. O privilégio da servidão: o novo proletariado de serviços na era digital. São Paulo: Boitempo, 2018. 
O Trabalho do Assistente Social no cuidado com Mulheres em Situação de Vulnerabilidade Social...

ANTUNES, Ricardo. Os sentidos do trabalho: ensaio sobre a afirmação e a negação do trabalho. São Paulo: Boitempo Editorial, 1999.

BAPTISTA, Myrian Veras. Planejamento social: intencionalidade e instrumentação. São Paulo: Veras Editora, 2000.

BARDIN, Laurence. Análise de conteúdo. Tradução de: Luís Augusto Pinheiro. São Paulo: Edições 70, 2016.

BARROCO, Maria Lúcia S. Não passarão! ofensiva neoconservadora e Serviço Social. Serviço Social \& Sociedade, São Paulo, n. 124, p.623-636, out./dez. 2015. Disponível em: https://www.scielo.br/pdf/sssoc/n124/0101-6628-sssoc-124-0623.pdf. Acesso em: 11 jan. 2019.

BRASIL. [Constituição (1988)]. Constituição da República Federativa do Brasil. Brasília, DF: Presidência da República, 1988. Disponível em:

http://www.planalto.gov.br/ccivil_03/constituicao/constituicaocompilado. htm. Acesso em: 2 nov. 2018.

BRASIL. Lei no 8.080, de 19 de setembro de 1990. Lei Orgânica da Saúde. Dispõe sobre as condições para a promoção, proteção e recuperação da saúde, a organização e o funcionamento dos serviços correspondentes e dá outras providências. Brasília, DF: Presidência da República, 1990. Disponível em: http://www.planalto.gov.br/ccivil_03/leis/L8080.htm. Acesso em: 2 nov. 2018.

BRASIL. Lei $n$ o 8.662 de 7 de junho de 1993. Dispõe sobre a profissão de assistente social e dá outras providências. Brasília: Presidência da República, 1993. Disponível em: http://www.planalto.gov.br/ccivil_03/leis/L8662.htm. Acesso em: 9 fev. 2019.

BRASIL. Ministério da Saúde. Política nacional de atenção básica. Brasília, DF: Presidência da República, 2017. Disponível em:

http://www.brasilsus.com.br/index.php/legislacoes/gabinete-do-ministro/16247-portaria-n2-436-de-21-de-setembro-de-2017. Acesso em: 6 dez. 2017.

BRASIL. Ministério da Saúde. Protocolos da atenção básica: saúde das mulheres. Brasília: Ministério da Saúde, 2016. Disponível em:

https://bvsms.saude.gov.br/bvs/publicacoes/protocolos_atencao_basica_saude_mulheres.p df. Acesso em: 6 dez. 2017.

BRASIL. Ministério da Saúde. Secretaria Executiva. Coordenação Nacional de DST/Aids. A política do Ministério da Saúde para atenção integral a usuários de álcool e outras drogas. Brasília: Ministério da Saúde, 2003. Disponível em: http://portalarquivos2.saude.gov.br/images /pdf/2015/marco/10/A-Pol--tica-do-Minist--rioda-Sa--de-para-Aten----o-Integral-ao-Usu--rio-de---Icool-e-Outras-Drogas--2003-.pdf. Acesso em: 2 nov. 2018.

BRASIL. Portaria no 1.412 de 10 de julho de 2013. Institui o Sistema de Informação em Saúde para a Atenção Básica (SISAB). Brasília, DF: Presidência da República, 2013. Disponível em: 
http://bvsms.saude.gov.br/bvs/saudelegis /gm/2013/prt1412_10_07_2013.html. Acesso em: 26 out. 2018.

BRASIL. Portaria no 3.124, de 28 de dezembro de 2012. Redefine os parâmetros de vinculação dos Núcleos de Apoio à Saúde da Família (NASF). Brasília, DF: Ministério da Saúde, 2012. Disponível em:

http://bvsms.saude.gov.br/bvs/saudelegis/gm/2012/prt3124_28_12_2012.html. Acesso em: 2 nov. 2018.

BRAVO, Maria Inês Souza; MATOS, Maurício Castro. Projeto ético-político do Serviço Social e sua relação com a reforma sanitária: elementos para o debate. In: MOTA, Ana Elizabete; BRAVO, Maria Inês de Souza; UCHÔA, Roberta; NOGUEIRA, Vera; MARSIGLIA, Regina; GOMES, Luciano; TEIXEIRA, Marlene (org.). Serviço Social e saúde: formação e trabalho profissional. São Paulo: Cortez, 2009. p. 197-217.

CAMARGO, Marisa; MENDES, Jussara Maria Rosa. Implicações do atual processo de gestão e organização do trabalho na atenção em saúde: o cotidiano da equipe multidisciplinar de uma unidade básica. In: GARCIA, Maria Lúcia Teixeira; COUTO, Berenice Rojas; MARQUES, Rosa Maria (org.). Proteção social no Brasil e em Cuba. Porto Alegre: EDIPUCRS, 2012.

CECCIM, Ricardo Burg. Interprofissionalidade e experiências de aprendizagem: inovações no cenário brasileiro. In: TOASSI, Ramona Fernanda Ceriotti. Interprofissionalidade e formação na saúde: onde estamos? Porto Alegre: Rede UNIDA, 2017.

CECÍLIO, Luiz Carlos Oliveira. As necessidades de saúde como centro estruturante na luta pela integralidade e equidade na atenção em saúde. In: PINHEIRO, Roseni; MATTOS, Ruben Araújo (org.). Os sentidos da integralidade na atenção e no cuidado à saúde. Rio de Janeiro: IMS ABRASCO, 2001. p. 113-126.

CONASS - CONSELHO NACIONAL DE SECRETÁRIOS DE SAÚDE. O sistema único de saúde e a qualificação do acesso. Brasília: CONASS, 2009. Disponível em:

http://www.conass.org.br/conassdocumenta/cd_19.pdf. Acesso em: 2 nov. 2018.

CONSELHO FEDERAL DE SERVIÇO SOCIAL - CFESS. Parâmetros para atuação de assistentes sociais na política de saúde. Brasília: CFESS, 2010.

FAGUNDES, Helenara; MOURA, Alessandra Ballinhas. Avaliação de programas e políticas públicas. Revista Textos \& Contextos, Porto Alegre, v. 8, n. 1, p. 89-103, jan./jun. 2009. Disponível em: http://www.redalyc .org/html/3215/321527164006/. Acesso em: 26 out. 2018.

GIL, Antônio Carlos. Como elaborar projetos de pesquisa. 4. ed. São Paulo: Atlas, 2012.

GIOVANELLA, Lígia. Atenção básica ou atenção primária à saúde? Cadernos de Saúde Pública, Rio de Janeiro, v. 34, n. 8, 2018. Disponível em: http://www.scielo.br/pdf/csp/v34n8/16784464-csp-34-08-e00029818.pdf. Acesso em: 10 out. 2018.

IAMAMOTO, Marilda Villela. O serviço social na contemporaneidade: trabalho e formação profissional. 23. ed. São Paulo: Editora Cortez, 2012. 
LISBOA, Teresa Kleba; PINHEIRO, Eliane Aparecida. A intervenção do serviço social junto à questão da violência contra a mulher. Katálysis, Florianópolis, v. 8, n. 2, jul. /dez. 2005.

MERHY, Emerson Elias; FRANCO, Túlio Batista. Trabalho em saúde. In: PEREIRA, Isabel Brasil; LIMA, Julio César França (org.). Dicionário da educação profissional em saúde. 2. ed. Rio de Janeiro: EPSJV, 2008. p. 427-432.

MINAYO, Maria Cecília de Souza. Conceitos, teorias e tipologias de violência: a violência faz mal à saúde individual e coletiva. In: SOUSA, E. R. (org.). Curso impactos da violência na saúde. Rio de Janeiro: EAD/ENSP, 2007. p. 24-35.

ORGANIZAÇÃO MUNDIAL DA SAÚDE - OMS. Relatório mundial sobre a prevenção da violência 2014. São Paulo: OMS, 2015.

ORGANIZAÇÃO MUNDIAL DE SAÚDE - OMS. Natureza, magnitude e consequências da violência sexual e da violência por parceiro íntimo. In: ORGANIZAÇÃO MUNDIAL DA SAÚDE. Prevenção da violência sexual e da violência pelo parceiro íntimo contra a mulher: ação e produção de evidência. Washington: OMS, 2012. p. 11-17. Disponível em:

http://apps.who.int/iris/bitstream/handle/10665

/44350/9789275716359_por.pdf;jsessionid=1B4D471D1D629055B46E90EEBF44BB52?seque nce=3. Acesso em: 2 nov. 2018.

PEDUZZI, M. Educação Interprofissional para o desenvolvimento de competências colaborativas em Saúde. In: TOASSI, Ramona Fernanda Ceriotti. Interprofissionalidade e formação na saúde: onde estamos? Porto Alegre: Rede UNIDA, 2017.

SPOSATI, Aldaíza. Modelo brasileiro de proteção social não contributiva: concepções fundantes. In: BRASIL. Ministério do Desenvolvimento Social e Combate à Fome. Concepção e gestão da proteção social não contributiva no Brasil. Brasília: MDS: Unesco, 2009. p. 13-56.

WAISELFISZ, Julio Jacobo. Mapa da Violência 2015: homicídio de mulheres no Brasil. Brasília: Flacso Brasil, 2015. 